\title{
Ridge Preservation for Implant Therapy: a Review of the Literature
}

\author{
Elizabeth M. Tomlin, Shelby J. Nelson and Jeffrey A. Rossmann*
}

Department of Periodontics, Texas A\&M University, Baylor College of Dentistry, Dallas, TX

\begin{abstract}
Healing of the extraction socket after tooth removal involves retention of the blood clot followed by a sequence of events that lead to changes in the alveolar process in a three dimensional fashion. This normal healing event results in a minimal loss of vertical height (around $1 \mathrm{~mm}$ ), but a substantial loss of width in the buccal-lingual plane (4-6 mm). During the first three months following extraction that loss has been shown to be significant and may result in both a hard tissue and soft tissue deformity affecting the ability to restore the site with acceptable esthetics. Procedures that reduce the resorptive process have been shown to be predictable and potentially capable of eliminating secondary surgery for site preparation when implant therapy is planned. The key element is prior planning by the dental therapist to act at the time of extraction to prevent the collapse of the ridge due to the loss of the alveolus.

Several techniques have been employed as ridge preservation procedures involving the use of bone grafts, barrier membranes and biologics to provide a better restorative outcome. This review will explore the evidence behind each technique and their efficacy in accomplishing site preparation. The literature does not identify a single technique as superior to others; however, all accepted therapeutic procedures for ridge preservation have been shown to be more effective than blood clot alone in randomized controlled studies.
\end{abstract}

Keywords: Bone grafts, guided bone regeneration, guided tissue regeneration, implant site preparation, ridge preservation.

\section{INTRODUCTION}

Tissues that surround and anchor a tooth in the maxillary or mandibular alveolar process make up the periodontium. The periodontium includes gingiva, connective tissue, cementum, periodontal ligament, and alveolar bone. The alveolar bone consists of cortical bone, cancellous trabeculae, and the alveolar bone proper, which is compact bone that composes the alveolus (tooth socket). Alveolar bone forms by an intramembranous ossification within the ectomesenchyme which surrounds a developing tooth. Initially, the bone is less organized woven bone and is eventually replaced with a more organized lamellar bone. Within lamellar bone, individual osteons with blood and nerves can be observed. The cells in the dental follicle near the alveolar bone side differentiate into osteoblasts, while the cells in the dental follicle between the first alveolar bone and developing root differentiate into cementoblasts on the root (dentin) side and fibroblasts in the future periodontal ligament space. The layer of osteoblasts lays down bone matrix to form the outer wall of the alveolar bone support [1].

Following tooth extraction, the alveolar bone undergoes remodeling. Difficult tooth extraction procedures may also result in additional bone loss due to the surgical trauma. If a tooth requires extraction, implant therapy is often considered one of the best options to replace a tooth functionally and

*Address correspondence to this author at the Texas A\&M University, Baylor College of Dentistry, Department of Periodontics, 3302 Gaston Avenue, Dallas, TX 75246; Tel: 214-828-8126; Fax: 214-874-4532;

E-mail: jrossmann@bcd.tamhsc.edu esthetically. However, sufficient alveolar bone volume and favorable architecture of the alveolar ridge are essential to obtain ideal functional and esthetic reconstruction following implant therapy [2]. To better understand the benefits of site preparation for implants, it is essential to have knowledge of the healing events that transpire with tooth extraction and steps that may lead to a better outcome with fewer surgical interventions. The purpose of this review paper is to highlight the benefits of ridge preservation at the time of extraction and provide an evidence-based rationale for adding this procedure to the implant protocol in site preparation.

\section{HEALING OF EXTRACTION SOCKETS}

In a study by Ohta, healing of extraction sockets in monkeys was explained as a process that occurred in five different stages. The first stage is described as the granulation stage and lasts around five days. The early granulation tissue first appears at the bottom of the socket and spreads laterally, up the socket walls. The second phase, the initial angiogenic stage, happens within the first week with the granulation stage. New trabeculae have begun to appear at the bottom of the socket, and the blood clot in the center has begun to shrink. The third phase he refers to as the new bone formation stage and begins two weeks after the tooth extraction. Sinusoid formations that began in the earlier phases yield bone trabeculae. At this point osteoid, can be detected. The bone formation follows the pattern of the sinusoid formations, which have mostly formed vertically starting in the apical region. The fourth stage is the bone-growth stage which is characterized by well developed, thickened trabeculae that now fill $2 / 3 \mathrm{rds}$ of the socket. This happens $4-5$ weeks 
after extraction. This woven bone is referred to as primary spongiosa. Some sinusoids are still forming in the coronal portion of the socket, while the apical portion appears to be more mature with less sinusoids. The final stage is the bone re-organization stage which is usually evident around six weeks after extraction. The primary spongiosa now develops into secondary spongiosa, or more lamellar bone, and is present in higher percentages towards the apical end of the residual socket [3].

The alveolar ridge will heal uneventfully after extraction in most cases, assuming retention of the primary blood clot. However, what is the price to the original volume of bone present prior to extraction during this natural process? Schropp et al. observed changes taking place following tooth extraction in humans. He reported the width of the alveolar ridge reduced up to $50 \%$ during the 12 month observation period after the extraction. This loss corresponded to a buccal-lingual change in dimension of 4.5 to $6.1 \mathrm{~mm}$. The finding that approximately two thirds of this reduction occurred within the first 3 months after tooth extraction also corresponded to earlier studies and emphasizes the need to take steps to reduce this resorptive process when implant therapy is considered. The percentage reduction was larger at molar sites compared to premolar sites. Furthermore, an average of 0.5 to $0.9 \mathrm{~mm}$ of vertical bone resorption can be expected by 12 months. The level of bone regenerated in the extraction socket never reached the coronal level of bone attached to the tooth surfaces mesial and distal to the extraction site. When Schropp analyzed the extraction sites, he found no major difference between the sites grouped according to region and jaw position [2].

Knowledge of the healing process at extraction sites, including bone resorption and remodeling is fundamental to our understanding. Changes occur at molecular, cellular, and tissue levels. Extraction of a tooth commences a cascade of inflammatory reactions [4]. Blood from severed vessels fill the socket creating a mixture of proteins and damaged cells. Blood platelets initiate a series of events that will ultimately lead to the formation of a fibrin clot, filling the entire socket, within the first 24 hours [5]. The coagulum, facilitated by growth factors, acts as a physical matrix and directs the movement of the inflammatory cells. Neutrophils and macrophages enter the socket to phagocytize bacteria and tissue debris. Released growth factors and cytokines induce and amplify the migration of mesenchymal cells and their synthesis within the coagulum [6]. On the fourth day, formation of immature connective tissue and epithelialization occurs. Within approximately seven days, replacement of the clot by granulation tissue starts at the periphery of the socket and osteoid forms at the base of the socket. By the $28^{\text {th }}$ day, immature bone composes two thirds of the extraction socket [7]. Investigations of ridge shape after tooth extraction demonstrate that the crestal ridge tends to shift lingually, when looking from the occlusal aspect. While laterally, the ridge concaves between the alveolar crests of adjacent teeth that still remain [8]. Misch proposed that the loss of crestal bone height and width of the buccal plate after tooth extraction is partially due to the constriction of the blood clot in the alveolus, and the remodeling of the labial cortical plates in response to inadequate blood supply after the extraction [9]. Ashman reported that tooth extraction creates a sequelae resulting in approximately $40 \%$ to $60 \%$ loss of bone height and width respectively within 2 to 3 years [10].

Atwood evaluated the resorption process in the postextraction anterior ridge of the edentulous mandible in several clinical and cephalometric studies [11-13]. Atwood and Coy divided the factors affecting the rate of resorption into four categories: anatomic, metabolic, functional and prosthetic. Anatomic factors included the thickness of the mucosa covering the ridge, the ridge relationship, the depth of the socket, the number of sockets present, the size, shape, and density of the ridges. Metabolic factors influence the cellular activity of osteoblasts and osteoclasts by way of nutritional, hormonal, and other metabolic facets. Functional factors involved the intensity, duration, frequency, and direction of forces applied to bone. These factors affected cellular activity, bone formation or resorption, depending upon a patient's resistance to the forces. Primarily, prosthetic factors concerned the type of prostheses involved and the materials and principles used to obtain a restorative goal. All categories as described by Atwood are interrelated in the resorption process [14].

Regarding the surfaces most affected by extractions, studies have demonstrated that post-extraction alveolar resorption was significantly greater in the buccal aspect in both jaws (Fig. 1). This phenomenon occurred because the anatomy of the facial alveolus presents as thin, primarily cortical bone, often knife-edged and unsupported by medullary bone. The presence of dehiscences or fenestrations increase postextraction alveolar remodeling and resulted in a buccal concavity in the alveolar bone [15]. The degree of residual ridge resorption closely related to the time since tooth extraction in both the maxilla and the mandible. The loss of tissue contour was greatest in the early post-extraction phase (within 6 months) [8]. Lastly, the healing of sockets in the maxilla progresses faster due to the greater vascular supply, than in the mandible, which often led to a faster resorption pattern [16].

As previously mentioned, the extraction of a tooth frequently led to a deficiency in ridge width and height of the alveolar crest, which affected the optimal placement of an implant (Fig. 2). Allegrini et al. reported that ridge preservation decreased early alveolar ridge width loss after tooth extraction. Bone replacement grafts for ridge preservation are defined by the American Dental Association as osseous autograft, allograft or non-osseous graft placed in an extraction site at the time of extraction to preserve ridge integrity. The success of bone grafting procedures is ultimately dependent upon revascularization and remodeling of the grafted bone into vital, load bearing bone. Autografts and other bone substitutes, allografts, xenografts, synthetic biomaterials and osteoactive agents help restore alveolar bone loss or maintain dental alveolar bone after extraction, supporting optimal placement of dental implants [17].

\section{BONE GRAFTING IN EXTRACTION SOCKETS}

Placing various bone graft materials inside the thoroughly debrided fresh extraction socket is the first step in ridge preservation. Grafts are generally classified according to their original source as follows: autograft (oral or extraoral), allograft (e.g. human freeze-dried bone), xenograft 


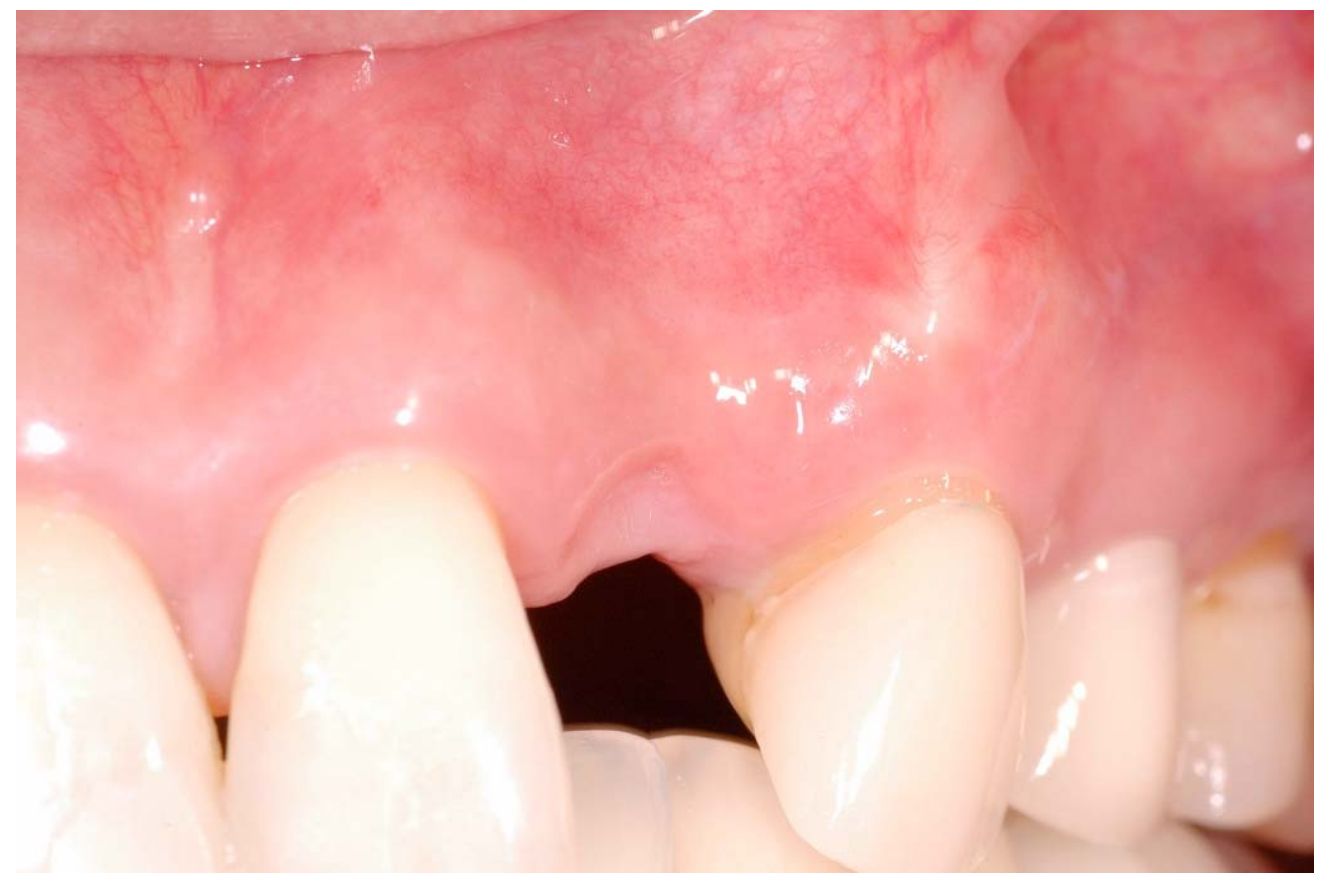

Fig. (1). Extraction site defect 6 months after tooth removal without ridge preservation. Note buccal depression and loss of vertical height at site \#10.

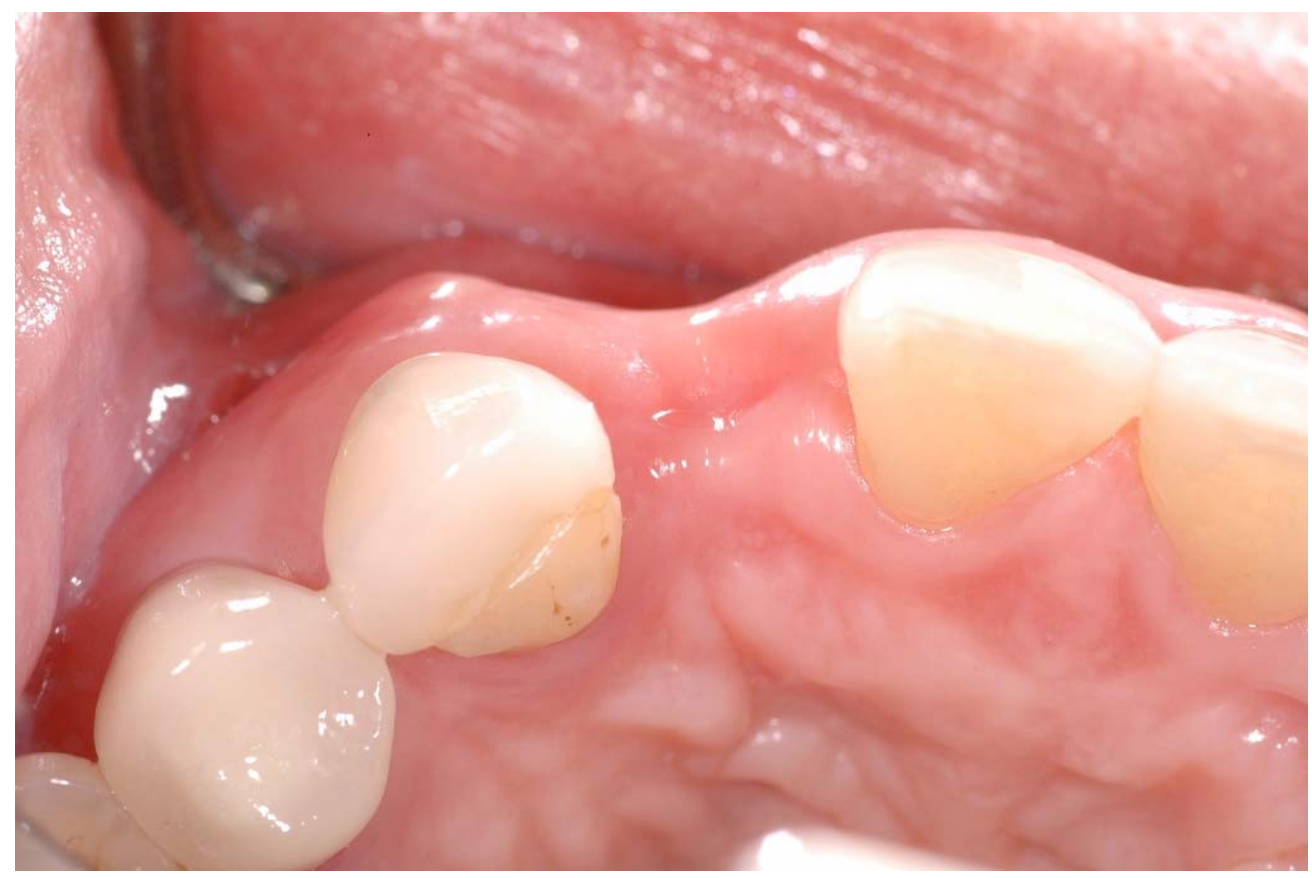

Fig. (2). Esthetic defect caused by tooth loss without ridge preservation requiring guided bone regeneration to adequately place an implant at the \#10 site for an acceptable outcome (occlusal view).

(bovine or porcine), and alloplasts or synthetic materials (hydroxyapatite, tricalcium phosphate, bioactive glass).

Iliac bone and marrow autografts have proven to be the most predictable graft materials for bone growth. However, they are no longer popular because of the necessity of harvesting from a secondary surgical site and the possible morbidity associated with the procedures [1]. Complications associated with the use of fresh iliac bone and marrow included root resorption and ankylosis, in regards to bone grafting around teeth [18]. Later, these complications were minimized by either freezing the bone graft in a storage medium or adding autologous intraoral bone to the harvested iliac crest bone graft mixture.

Intraoral autogenous bone grafts have been harvested from various intraoral sites including edentulous ridges, the maxillary tuberosity, post-extraction healing sites, and tori or exostoses. The source of intraoral bone also is important. When bone is predominantly cortical in nature, it has little osteogenic potential. Cancellous bone, which contains hematopoietic marrow, such as red bone marrow from the maxil- 
lary tuberosity or from healing tooth sockets ( 8 to 12 weeks after extraction), provides better osteogenic potential. Particulate bone is harvested using several different techniques. Osseous coagulum is bone obtained using high or low speed burs mixed with blood [19]. Bone blend is intraoral, cortical or cancellous bone harvested and placed into a sterile amalgam capsule with a pestle and triturated for 60 seconds [20]. Additionally, bone may be collected using hand instruments such as a chisel, osseous collection device, or back action hoe. Besides autogenous bone, allografts, xenografts, and alloplasts, usually available in a block or particulate form, can serve as an alternative graft material. Iasella et al. [21] demonstrated the benefit of using alternative bone graft materials for site preservation following tooth removal.

Allografts consist of tissue transferred from one individual to another genetically dissimilar individual of the same species. This type of graft material has become popular because of the lack of a secondary surgical site and decreased host morbidity. The main benefit of an allograft bone graft is the ability to obtain essentially unlimited amounts of graft material. These grafts can be categorized as demineralized frozen or freeze-dried bone (DFDBA) or mineralized frozen or freeze-dried bone (FDBA). FDBA provides an osteoconductive scaffold and elicits slower resorption than DFDBA when implanted in mesenchymal tissues [22]. Urist suggested that using demineralized cortical bone may have the added advantage of exposing bone morphogenic proteins (BMPs), causing it to be osteoinductive as well as osteoconductive. Osteoinduction involves the elicitation of mesenchymal cell migration, attachment and osteogenesis when implanted in well-vascularized bone and induction of endochondral bone formation when implanted in tissues that would otherwise not form bone [23]. Schwartz et al. studied DFDBA samples from six different bone banks and different lots within the same bank, the authors concluded there was a large variation between bone banks as well as between lots within the same bank. Possible reasons for the disparities were attributed to age, sex and medication taken by the donor, processing of the sample (demineralization time, sterilization method, particle size, etc.) and the time between death and harvest from the donor [24].

Shapoff et al. studied the particle size of FDBA for hard tissue grafting around teeth, and reported that 100-300 um was the ideal particle size that would allow the bone particles to remain at the grafted site for a sufficient length of time while optimizing vascularization. Particles that are too small $(<125 \mathrm{um})$ provoke a macrophage reaction and are resorbed too quickly with little to no bone formation. Particles that are too large may restrict inter-particle space for vascularization and may be sequestered [25]. Zaner and Yukna also studied particle sizes of autogenous bone obtained by different collection methods and FDBA. This study also involved guided tissue regeneration around teeth. They found that the bone blend had the smallest and most uniform particle size $(21 \mathrm{x}$ $105 \mathrm{um}$ ), osseous coagulum and FDBA had particle sizes of 300-500 um, and chiseled bone chips had the largest and least uniform particle size ( $789 \times 1559$ um). In addition, they suggested that the most appropriate graft particles size was $380 \mathrm{um}$. This particle size would produce the minimal pore size of 100 um needed between particles to allow for vascularization and bone formation to occur [26]. DFDBA is also available in various sizes from 20-100 um and 100-300 um (lamellar bone or laminar bone) and as blocks of ilium [23].

Although donor tissue has the potential to transmit disease, there have been no reports of viral contamination or acquired pathology from DFDBA or FDBA [23-27]. With the rigorous screening and testing of donor material, the possibility of disease transfer is approximately one in two million [28]. Freezing the bone allograft reduces the risk of disease transfer to one in eight million [29]. Mellonig et al. [27] evaluated HIV-spiked human cortical bone and bone obtained from an AIDS patient by testing for the presence of HIV both before and after processing. The acid decalcification process and use of virucidal agents destroyed the HIV, thus demonstrating the safety of DFDBA.

Wood and Mealey conducted a study in which 40 extraction sockets were divided into 2 groups. Either DFDBA or FDBA was randomly selected and grafted in the extraction sockets. Histologic samples were obtained at 4-5 months post graft, during implant placement. There were no significant differences when comparing changes in alveolar ridge dimensions of the two groups. DFDBA had a significantly greater percentage of vital bone at $38.42 \%$ versus FDBA at $24.63 \%$. The DFDBA group also had a significantly lower mean percentage of residual graft particles at $8.88 \%$ compared to FDBA at $25.42 \%$. The authors concluded that this study provided the first histologic and clinical evidence directly comparing ridge preservation with DFDBA versus FDBA in humans and demonstrated significantly greater new bone formation with DFDBA [30].

Hoang and Mealey evaluated the use of DFDBA bone putty with different particle sizes. Molar tooth extraction and ridge preservation were performed in 20 participants for each treatment group. Approximately 20 weeks after grafting, core biopsies were obtained during implant placement and analyzed under light microscopy. Specimens were analyzed for the percentage area of vital bone, residual graft particles, and non-mineralized structures (connective tissue/other nonmineralized tissue $[\mathrm{CT}])$. Changes in alveolar ridge dimensions were also determined. Sixteen participants in the single particle size (SPS) group and 14 in the multiple particle size (MPS) group completed the study. The SPS group (particle size range from $125-710$ microns) had a mean of $49 \%$ vital bone, $8 \%$ residual graft, and $43 \%$ CT. The MPS group (SPS size plus $2-4 \mathrm{~mm}$ particles in putty) had $53 \%, 5 \%$, and $42 \%$, respectively. Patients in both groups lost a mean of $<1 \mathrm{~mm}$ alveolar height on the buccal and lingual aspects and $<1.5 \mathrm{~mm}$ of total ridge width. There were no statistically significant differences between the two groups for any clinical or histologic parameters [31].

A recent study by Eskow and Mealey [32] compared the use of cortical versus cancellous FDBA from a single donor in ridge preservation. 38 patients were enrolled in the study and histologic analysis was performed on 33 cores obtained at 18 weeks following extraction. The histology showed more residual graft material present in the cortical samples and only $13-16 \%$ new bone formation respectively for cancellous and cortical FDBA at 18 weeks. The dimensional ridge changes for both materials were similar and both showed loss of ridge height and width with the cortical FDBA preserving more lingual/palatal ridge height than the 
cancellous FDBA. In 11 of 35 patients the residual ridge at implant placement required additional bone grafting on the buccal aspect due to thin remaining bone or dehiscences, thus confirming other studies showing ridge preservation techniques will improve the outcome for site preparation for implants with some loss of bone still expected [33].

Rummelhart et al. [34] found no difference in clinical parameters when DFDBA was compared to FDBA in periodontal defects. Furthermore, Sanders et al. [35] concluded that mixing DFDBA with autogenous bone can increase the volume of bone available for grafting as well as enhance clinical outcomes when attempting to regenerate bone, especially in 1- and 2-walled periodontal defects.

Xenografts are tissue grafts transferred from one species to a different species. It has been observed in some shortterm studies that while the placement of biomaterial in alveolar sockets may promote bone formation and ridge preservation, the graft may also delay healing. A study evaluating the long-term effect on bone formation and the amount of ridge augmentation that can occur by placement of BioOss collagen ${ }^{\circledR}$ (Geistlich Pharma North America, Inc.) a xenogeneic graft in extraction sockets in five beagle dogs was completed. Non-grafted sites served as the control. The Bio-Oss collagen ${ }^{\circledR}$ served as a scaffold for tissue modeling, but not new bone formation. The Bio-Oss collagen ${ }^{\circledR}$ placed into the extraction sockets when compared to the non-grafted sites showed improved preservation of the alveolar process and ridge profile. The clinicians concluded that the placement of a biomaterial in an extraction socket may modify remodeling and counteract normal marginal ridge contraction following tooth removal [36]. A human study using 25 patients compared placing Bio-Oss collagen ${ }^{\circledR}$ into intact extraction sockets versus controls (clot only) in 39 sites. Their results after 12 weeks showed new bone formation in augmented sites (test) was only 25\% compared to nonaugmented sites (control) of 44\% [32]. This suggests a delay in bone formation in grafted sites as found in other studies.

The most commonly used xenograft is deproteinized bovine bone mineral (DBBM) or more commonly known by the brand name Bio-Oss ${ }^{\circledR}$ (Geistlich Pharma). A study conducted in 2000 evaluated extraction sockets grafted with DBBM at 9 months. Histologically, the specimens were analyzed in the coronal, mid, and apical third of the sockets. The average amount of vital bone ranged from $26.4-35.1 \%$ with the most vital bone present in the apical portions and the least present in the coronal portion. The coronal portion of the socket was mostly connective tissue (63.9\%). The DBBM graft material was still present at 9 months. The authors noted that it was present uniformly throughout the socket and averaged an overall 30\% residual graft [37]. One year later, the same authors did a follow up study in which they analyzed the amount of woven versus lamellar bone present in the 3 socket regions. In addition the authors found that while DBBM still remained in the socket at 9 months, no connective tissue was in contact with the graft, thus allowing the authors to claim that DBBM is a biocompatible socket filler that can be used in ridge preservation procedures [38]. Another study that found DBBM as a favorable graft for ridge preservation compared DBBM to irradiated cancellous allograft (ICA), and to solvent-dehydrated allograft
(SDA) when used to preserve extraction sockets [39]. Core biopsies were obtained 4-6 months after graft placement and were evaluated histomorphometrically. Most of the DBBM particles that were still present were described as being in intimate contact with cortical bone. Very few particles were in contact with stromal connective tissue suggesting no evidence of fibrous encapsulation. In addition, there was a minimal inflammatory cell infiltrate verifying the grafts antigenicity. The DBBM particles were mainly associated with osseoconduction but in close contact with new bone formation. The authors concluded that DBBM grafts may be useful in defects where new bone is desired and a slower resorption rate of the graft is preferred [39]. These and many other studies have proven xenografts to be a viable treatment option for ridge preservation.

Alloplasts are a synthetic graft material which is inert and implanted into tissue. Hydroxyapatite, tricalcium phosphate, calcium sulfate and bioactive glass polymers are common examples of synthetic bone graft materials [40]. This graft material is inert, osteoconductive filler material, which serves as a nidus or scaffold for new bone formation. Alloplasts have been shown to result in defect fill, stabilization of the remaining osseous structure, clinical attachment gain, and decreased probing depths [40, 41].

In 1998 a study was conducted in which 3 groups were classified and treated with bioactive glass. The first group of patients had class II or class III residual ridge defects (Siebert classification). This group was treated with a ridge augmentation procedure. The ridge was surgically split and bioactive glass was placed as a bone graft. The second group had extraction sockets that were treated with bioactive glass for ridge preservation at the time of tooth extraction. The third group was treated as the control and the teeth were extracted and allowed to heal without any graft. The results showed there was no significant difference in the ridge preservation group versus the ridge augmentation group. The bioactive glass was able to maintain the alveolar ridge width and gain enough width in the augmentation cases. The control group did not show significant differences in buccallingual dimension; however the vertical resorption was significant [12]. In 2002 another randomized control trial was completed. Seventeen teeth were extracted and bioactive glass was placed as the ridge preservation graft. At the time of implant placement a trephine core was obtained for histological analysis. The authors stated in the conclusions that the study draws attention to the long healing time required to achieve even a small amount of new bone incorporation into the graft, as seen histologically. However, the success rate of the implants was not affected [42].

Hydroxyapatite as a graft material is another common synthetic bone graft. In 2004, Froum et al. evaluated extraction sockets grafted with hydroxyapatite and noted approximately $31 \%$ vital bone present at 6-8 months [43]. In that same study, bovine bone yielded an average of $29.75 \%$ vital bone. All of the extraction sites had buccal defects and there was no attempt to gain primary closure [43]. In 2002 the same authors completed a similar study in which he compared bioactive glass to demineralized bone allograft (DFDBA). There were no barrier membranes used in this study. Instead primary closure was achieved after the grafts 
were placed. 6-8 months after graft placement, the bioactive glass yielded $59.5 \%$ vital bone with $5.5 \%$ residual graft remaining. The sites treated with DFDBA yielded $34.7 \%$ vital bone with $13.5 \%$ residual graft. The results were statistically significant for amount of residual graft present. The control groups in this study were allowed to heal by blood clot and primary closure alone. These sites yielded $32.4 \%$ vital bone. The authors concluded that although the differences in percent vital bone were not statistically significant among the 3 treatment groups in this pilot study, bioactive glass material was observed to act as an osteoconductive material which had a positive effect on socket healing at 6 to 8 months post extraction [44].

Finally, sponges made of collagen or polylactic/polyglycolic acid is another alternative material that can be used in ridge preservation. Serino et al. conducted studies with Fisiograft ${ }^{\circledR}$ a synthetic co-polymer composed of polylactic and polyglycolic acids, used as a space filler during ridge preservation. Full thickness flaps were reflected and half of the extraction sockets were filled with the sponge and the other half left to heal by blood clot alone. No attempt was made to achieve primary closure. At 6 months the implants were placed and core biopsies obtained for histological analysis. Ridge dimensions were not significantly different between any of the groups. Histologically the test sites revealed new bone that was mineralized and well structured. No residual graft material was detected in the extraction sites [45]. Five years later the authors repeated the same clinical trial with the exception of not waiting 6 months to place the implant. In this study they re-entered the grafted sites and controls at 3 months. Histological analysis revealed that the grafted sites had healed with mineralized, well organized bone with no residual graft particles [46].

A technique described by Sclar named the Bio-Col technique involved the placement of DBBM particles in the extraction socket and then covered with a collagen plug or membrane sutured into place. Results yielded an adequate ridge preservation that allowed implant placement [47]. Collagen sponges have also been used as carriers for placing other graft materials. In one study, twenty-four consecutive subjects in need of extraction of maxillary premolars were recruited. Subjects were randomly assigned to the test group using a cell-binding polypeptide (P15), hydroxyapatite matrix and bioabsorbable collagen wound dressing material or control group (bioabsorbable collagen wound dressing material only). Data were recorded at 1, 2, 4, 8, and 16 weeks after ridge preservation procedures. At 16 weeks, a reentry surgery was performed, clinical measurements were repeated, and bone core biopsies were obtained for histomorphometric analysis prior to implant placement. On average a reduction of $0.15 \pm 1.76 \mathrm{~mm}$ in height and $1.31 \pm 0.96 \mathrm{~mm}$ in width was seen for the test sites and for controls a $0.56 \pm$ $1.04 \mathrm{~mm}$ reduction in height and a $1.43 \pm 1.05 \mathrm{~mm}$ reduction in width were observed. The difference in height was significant. Histology revealed mean bone density was significantly superior in the test group $(2.08 \pm 0.65$ versus $3.33 \pm 0.65)$. Histomorphometric analyses revealed similar percentages of bone vitality (test: $29.92 \% \pm 8.46 \%$; control: $36.54 \% \pm$ $7.73 \%$ ). Comparable percentages of bone marrow and fibrous tissue also were observed (test: $65.25 \% \pm 6.41 \%$; con- trol: $62.67 \% \pm 7.41 \%$ ). Only $6.25 \%$ of the Putty P15 particles remained at 4 months in the analyzed biopsies [48].

In another study eighty patients requiring local alveolar ridge augmentation for buccal wall defects $(\geq 50 \%$ buccal bone loss of the extraction socket) in maxillary anterior teeth immediately following tooth extraction were enrolled. Two sequential cohorts of 40 patients each were randomized in a double-blinded manner to receive $0.75 \mathrm{mg} / \mathrm{ml}$ or $1.50 \mathrm{mg} / \mathrm{ml}$ rhBMP-2 (bone morphogenic protein) with acellular collagen sponge (ACS); placebo (ACS alone); or no treatment (blood clot only) control. Efficacy was assessed by evaluating the amount of bone induction, the adequacy of the alveolar bone volume to support an endosseous dental implant, and the need for a secondary augmentation. Assessment of the alveolar bone indicated that patients treated with $1.50 \mathrm{mg} / \mathrm{ml} \mathrm{rhBMP-2/ACS} \mathrm{had} \mathrm{significantly} \mathrm{greater}$ bone augmentation compared to controls $(\mathrm{P} \leq 0.05)$. The adequacy of bone for the placement of a dental implant was approximately twice as great in the rhBMP-2/ACS groups compared to no treatment or placebo; with an increasing gradient based on increasing dosage of rhBMP-2. In addition, bone density and histology revealed no differences between newly induced and native bone [49].

\section{SITE DEVELOPMENT THROUGH RIDGE PRESER- VATION}

The principles behind implant site development, including ridge preservation and guided bone regeneration, originated from the principles of guided tissue regeneration. The concept of selective cell repopulation has been useful in theorizing about enhancing site development for implant placement. Bone can be regenerated by using a barrier membrane at an extraction site or deficient alveolar ridge. At the time of tooth extraction, the socket can be augmented with a graft material and sealed with a barrier membrane or a membrane may be used without graft material in the socket. Rose et al. termed this procedure ridge preservation. Similarly, an alveolar ridge with a volumetric deficiency can be improved with the use of graft material and a barrier membrane. This procedure termed guided bone regeneration (GBR) is a commonly used technique for osseous ridge augmentation $[1,50]$.

Iasella et al. [21] performed a 6-month randomized, controlled, blinded clinical study to establish whether ridge preservation would prevent post-extraction resorptive changes, assessed by clinical and histologic parameters. Twenty-four randomly selected patients aged 28 to 76, requiring a non-molar extraction, received either extraction alone (control) or ridge preservation (test) using tetracycline hydrated freeze-dried bone allograft (FDBA) and a collagen resorbable membrane. Following extraction, the examiners collected horizontal and vertical ridge dimensions using a modified digital caliper and an acrylic stent respectively. Prior to implant placement, they obtained a $2.7 \times 6.0 \mathrm{~mm}$ trephine core for histologic analysis. The width of the test group decreased from 9.2 to $8.0 \mathrm{~mm}$, while the width of the control group decreased from 9.1 to $6.4 \mathrm{~mm}$, a difference of $1.6 \mathrm{~mm}$. The test group showed improved results by losing 
less ridge width, but both the control and test groups lost width. The majority of the resorption occurred from the buccal. The maxillary sites lost more width than the mandibular sites. The vertical change for the test group was a gain of $1.3 \mathrm{~mm}$ versus a loss of $0.9 \mathrm{~mm}$ for the control group, a height difference of $2.2 \mathrm{~mm}$. Histologic analysis revealed more bone in the test group: about $65 \%$ versus $54 \%$ in the control group. The test group included both vital bone (28\%) and non-vital (37\%) FDBA fragments. They concluded that ridge preservation using FDBA and a collagen membrane improved ridge height and width dimensions when compared to extraction alone.

If implant therapy is the desired course of treatment, the goal is to give the patient a stable replacement for their tooth (teeth) with the most esthetic outcome possible. Single tooth restorations should be approached with the goal of the soft tissue contour being as identical as possible to the natural tooth. The soft tissue contour is determined by the underlying bone. The most important factors are the height of the alveolar bone and the thickness of the facial plate after extraction. Adequate bone allows the implant to be placed in the most ideal restorable position in a three dimensional aspect which will yield higher long term success.

Salama et al. published on topographical analysis of socket bone after extraction. Recommendations for augmentation were based on the following classification system [51]. After a tooth is extracted, if all of the bone and the soft tissue is preserved, Salama termed this a Type I extraction socket. The prescribed treatment for this site is to preserve the dimensions. Ridge preservation can include placing a bone graft and a membrane, a bone graft alone, a membrane alone, or simply letting the socket heal naturally with a blood clot. A type II socket is defined as an extraction socket with a labial defect, such as a buccal dehiscence or a fenestration due to an endodontic lesion or root prominence. This defect will require a ridge augmentation procedure instead of a preservation procedure. This type of defect should at the least be treated with a bone graft and a membrane. A type III socket is one in which there is a buccal defect and an interproximal vertical defect. Salama states that these defects should be treated with orthodontic extrusion first to achieve the most esthetic results, especially in the maxillary anterior region [51].

The use of ridge preservation techniques are used to prevent residual ridge defects, and thus increase satisfaction with respect to esthetics and function. Adequate buccal plate thickness at the time of implant placement is a key component of successful and esthetic implant therapy. During implant placement a thickness of facial bone of at least $1.8 \mathrm{~mm}$ after the final osteotomy is drilled resulted in significantly less bone resorption than facial plates that were less than $1.8 \mathrm{~mm}$ [52]. Since most implant systems design a final osteotomy that is $80 \%$ the size of the implant diameter, an estimate of $1.44 \mathrm{~mm}$ of buccal bone thickness remained after the implant was placed. Whether this critical parameter can be used as a guideline for buccal plate thickness after tooth extraction is yet to be determined. A study by Braut et al. evaluated the facial bone thickness in the anterior maxilla in 125 cone beam CT scans. They measured the width at two points; $4 \mathrm{~mm}$ from the CEJ and at the middle of the root in
498 teeth. Their results showed the majority of teeth had $<1 \mathrm{~mm}$ of bone thickness $(62.9 \%$ at $4 \mathrm{~mm}$ from the CEJ, $80.1 \%$ at the midroot) with a statistically significant decrease in facial bone thickness from the first premolar to the central incisors. The facial bone at the crest was either missing or thin in $90 \%$ of the teeth evaluated by CBCT [53]. This study confirms the value of ridge preservation at the time of extraction and the need to support that thin alveolus to reduce buccal bone resorption.

\section{BARRIER MEMBRANES}

Many types of materials were developed to serve as barrier membranes. These different membranes are distinguished as either non-resorbable or resorbable membranes.

\section{NON-RESORBABLE MEMBRANES}

Nyman and colleagues initially used a membrane constructed from Millipore ${ }^{\circledR}$ (cellulose acetate) filters. As this technique became more prevalent, the first commercial membrane was produced from Teflon ${ }^{\circledR}$, an expanded polytetrafluoroethylene (e-PTFE). This membrane consisted of 2 parts: a collar portion, having open pores to allow ingrowth of connective tissue and to prevent epithelial migration; and an occlusive portion, preventing the flap tissues from coming into contact with the root surface [54]. Later, the membrane was redesigned with a stiff central portion to treat osseous defects, with the understanding that the space defined and protected by the membrane determined the volume of the tissue to be regenerated $[54,55]$. Titanium was built into the membrane for treatment of both osseous and periodontal defects [55]. Successful use of non-resorbable membranes in GTR therapy led to application of these membranes in GBR procedure.

Buser et al. [56] was one of the first clinicians to report successful ridge augmentation with GBR in humans using an e-PTFE membrane and tenting pins. He described twelve patients who received alveolar ridge augmentation prior to dental implant placement. Surgical protocol involved reflection of a mucoperiosteal flap, and perforations of the cortical plate within the defect using a round bur to increase blood supply to the graft. Titanium mini-screws placed within the defect helped to provide tenting support to the overlying ePTFE membrane. Following six to ten months of healing, the authors demonstrated an increase in bone volume sufficient to allow placement of dental implants in nine of the twelve sites. The gain in new bone formation ranged from 1.5 to $5.5 \mathrm{~mm}$. The authors concluded that the biologic principle of osteopromotion by exclusion was highly predictable for ridge enlargement or defect regeneration under the prerequisite of complication-free healing.

However, complications during the healing following placement of non-resorbable membranes were commonplace. Non-resorbable membranes must be recovered at a second surgery, which can disturb healing [50]. Membrane exposure created by variable amounts of flap sloughing during healing has been a recurrent post-surgical complication associated with the use of non-resorbable membranes [57]. The exposed porous membrane facilitated adhesion of bacteria. GBR failures, as high as $31 \%$, due to membrane expo- 
sure have been reported [58]. Membrane exposure creates a communication between the oral environment and newly forming tissues, increasing the possibility for infection and decreasing the probability of regeneration. Machtei [59] performed a meta-analysis to evaluate the effects of membrane exposure on GTR and GBR procedures. In cases where there was exposure, the amount of new bone formed was $0.56 \mathrm{~mm}$, whereas sites where membranes remained covered gained $3.01 \mathrm{~mm}$ of new bone. Early membrane exposure, during the first 6 weeks following surgery appears to be more detrimental than late exposure following GBR techniques.

To counteract some complications due to non-resorbable porous membrane (e-PTFE) exposure the development of a high-density polytetrafluoroethylene (d-PTFE) non-porous membrane used specifically for ridge preservation following extraction has been utilized. A retrospective study based in a private practice demonstrated the use of d-PTFE left exposed following extraction and maintained in place for 4 weeks resulted in significant retention of the alveolar ridge in 276 sockets. Although no controls were used in this study, measurements were taken at baseline and one year later to verify the amount of bone loss at specific points using a stent. The advantage of the d-PTFE over e-PTFE was that no primary coverage was attempted and therefore, no releasing incisions to manipulate the flap were used. The exposed d-PTFE did not affect the outcome and the non-porous membrane appears impenetrable to bacteria due to its surface characteristics [60]. The use of non-porous d-PTFE membranes was found to have results equivalent to e-PTFE membranes in GTR and GBR studies when primary closure of the sites was also obtained [61, 62].

\section{RESORBABLE MEMBRANES}

There are three types of biologically resorbable membranes: 1) polyglycoside synthetic copolymers: polylactic acid - Guidor ${ }^{\circledR}$ (Sunstar Americas, Inc.), polyglactide - Resolute (W.L. Gore and Associates Inc.), polyglactin 910 - Vicryl (Ethicon division Johnson \& Johnson Medical), 2) collagen and 3) calcium sulfate - CalcigenOral (Biomet 3i).

Collagen membranes, as all resorbable membranes, do not normally require a second surgery for retrieval. Patients appreciate the elimination of a second surgery, in addition to less morbidity. Collagen is the principal component of connective tissue and provides structural support for tissues throughout the body [50]. Collagen is a hemostatic agent. It possesses the ability to stimulate platelet attachment and to enhance fibrin linkage, which may assist initial clot formation and stabilization, leading to enhanced regeneration [63]. In addition, collagen is chemotactic for fibroblasts in vitro. This property could possibly enhance cell migration in vivo [64]. Collagen membranes are easy to manipulate and adapt nicely to the alveolar topography as well. Patients tolerate collagen, a weak immunogen, very well [50, 65-67].

Acellular dermal matrix (ADM) is derived from human donor skin tissue. It is commercially available from tissue banks sanctioned by the American Association of Tissue Banks (AATB). The donor tissue undergoes multiple washing steps to remove the epidermis and the various cells that may cause graft rejection. The tissue is then preserved through a patented freeze-drying process that prevents ice crystals from forming. ADM was initially known for its use in skin grafting for burn patients, and various plastic and orthopedic reconstructive procedures. Primarily, in dentistry, $\mathrm{ADM}$ is utilized in root coverage procedures. Extensive studies have proven its efficacy in these procedures.

Luczyszyn et al. [68] used ADM as a membrane for ridge preservation. The aim of this study was to evaluate the role of acellular dermal matrix (ADM), associated with a resorbable hydroxyapatite (RHA) bone graft in regeneration to prevent bone loss after tooth extraction. They selected fifteen patients, with at least 2 noncontiguous, single-rooted teeth in need of extraction. In group 1, ADM covered extraction sockets alone; and in group 2, ADM covered the alveoli filled with RHA. Re-entry surgeries and biopsies were performed after 6 months. Both groups illustrated preservation of ridge thickness. However, the means were significantly greater $(\mathrm{P}<0.05)$ for group 2 when compared to group 1 $(6.8 \mathrm{~mm} \pm 1.26$ versus $5.53 \mathrm{~mm} \pm 1.06)$. The histologic analysis showed small bone formation in some samples for group 2, where the presence of a highly vascularized fibrous connective tissue surrounding the particles was a common finding. Based on the results, Luczyszyn et al. [68] concluded that the ADM was able to preserve ridge thickness and that the additional use of RHA favored the preservation of the ridges along with an increase in the width of keratinized tissue.

\section{SYSTEMATIC REVIEWS}

In a systematic review conducted on ridge preservation techniques for implant therapy, the authors evaluated $37 \mathrm{hu}$ man studies meeting their criteria. From these studies, nine different methods of ridge preservation were identified [69]. The most common technique being placement of a bone graft in the extraction socket, covered by a membrane and flap advancement to achieve partial or complete primary closure. The second most common technique involved placing a bone graft in the socket and then simply advancing the flap or rotating the flap to achieve closure without the use of a membrane. The third was to place a membrane alone and then achieve primary closure with flap advancement. All other methods involved any combination of the grafting materials discussed in this review article. Flap elevation was required for all techniques involving a membrane, but not for all procedures with a graft or sponge. Comparative studies that had a control of normal healing showed that ridge preservation using a membrane alone or in combination with a grafting material had similar changes in vertical height over a 6 month healing period, but a significantly reduced change in horizontal width of the ridge. The authors stated there is strong evidence that ridge preservation significantly maintains ridge width and height, with most grafting materials being equally effective and only slight differences between them. [69] They found that primary closure was not always necessary or recommended. They concluded there is no evidence to support the superiority of one technique over another and all were effective in limiting horizontal and vertical ridge alterations in post-extraction sites.

Recent systematic reviews have been published on alveolar ridge preservation. Horvath et al. included 8 randomized 
Table 1. Treatment modalities and expected dimensional changes.

\begin{tabular}{|c|c|c|c|c|}
\hline & Control Sites (No Treatment) & Bone Graft Only & Membrane Only & $\begin{array}{c}\text { Combined Bone Graft + } \\
\text { Membrane }\end{array}$ \\
\hline $\begin{array}{l}\text { Horizontal bone } \\
\text { changes }\end{array}$ & $\begin{array}{c}-2.51 \mathrm{~mm} \\
\text { Range: } 0.16-4.5 \mathrm{~mm} \\
(\text { loss })\end{array}$ & $\begin{array}{c}-1.18 \mathrm{~mm} \\
\text { Range: } 0.75-2.0 \mathrm{~mm} \\
(\text { loss })\end{array}$ & $\begin{array}{c}-0.08 \mathrm{~mm} \\
\text { Range: } 0.1 \text { (loss) }-2.90 \mathrm{~mm} \\
\text { (gain) }\end{array}$ & $\begin{array}{c}+0.47 \mathrm{~mm} \text { (gain) } \\
\text { Range: } 3.48 \text { (loss) }-3.27 \mathrm{~mm} \\
\text { (gain) }\end{array}$ \\
\hline Vertical bone changes & $\begin{array}{c}-2.07 \mathrm{~mm} \\
\text { Range: } 0.8-5.24 \mathrm{~mm} \text { (loss) }\end{array}$ & $\begin{array}{c}-1.31 \mathrm{~mm} \\
\text { Range: } 0.48-2.48 \mathrm{~mm} \\
(\text { loss })\end{array}$ & $\begin{array}{c}+0.14 \mathrm{~mm} \text { (gain) } \\
\text { Range: } 0.38 \text { (loss) }-1.30 \mathrm{~mm} \\
\text { (gain) }\end{array}$ & $\begin{array}{c}-0.15 \mathrm{~mm} \\
\text { Range: } 0.02 \text { (loss) }-1.3 \mathrm{~mm} \\
\text { (gain) }\end{array}$ \\
\hline $\begin{array}{l}\text { Percentage of vital } \\
\text { bone }\end{array}$ & $\begin{array}{c}42.4 \% \\
\text { Range: } 25.7-54.0 \%\end{array}$ & $\begin{array}{c}46.2 \% \\
\text { Range: } 32.4-59.5 \%\end{array}$ & N.A. & $\begin{array}{c}31.7 \% \\
\text { Range: } 28-35.5 \%\end{array}$ \\
\hline
\end{tabular}

Results are averages found from multiple studies using several different materials with follow-up of $4-6$ months healing. N.A. = no studies available. Control sites are all extraction without augmentation (Data compiled from 14 studies in systematic reviews)

controlled trials and 6 controlled clinical trials in their review citing post-extraction resorption might be limited, but cannot be eliminated through ridge preservation. Additional conclusions from their review include: 1 . The magnitude of ridge resorption is more pronounced in the horizontal dimension than the vertical; 2 . The presence of intact socket walls and primary flap closure are associated with favorable results; 3 . Conflicting evidence exists on the benefit of alveolar ridge preservation on the histological level since it does not routinely promote de novo hard tissue formation and some graft materials may interfere with healing [70]. Morjaria et al. reviewed 42 papers and included 9 in their review of randomized controlled trials. They found a range in loss of ridge width after extraction of $2.46-4.56 \mathrm{~mm}$ for control sites compared to a loss of $1.14-2.5 \mathrm{~mm}$ for test sites and a loss of ridge height ranging from $0.9-3.6 \mathrm{~mm}$ for control sites versus a gain of 1.3 to a loss of $0.62 \mathrm{~mm}$ in test sites. All included studies had a follow-up time after extraction of at least 3 months. The studies which included histological analysis found that a large proportion of the ridge preservation in test sites was due to unresorbed graft material [71]. Vignoletti et al. included 14 studies that met their criteria and used 9 in a meta-analysis. They concluded that ridge preservation significantly reduced the loss of alveolar bone in both the vertical and horizontal component although scientific evidence could not provide clear guidelines in regards to the type of biomaterials or surgical technique preferred. However, the most favorable results were found with the use of barrier membranes, flapped procedures versus flapless and primary closure of the flaps [72]. Additionally, a systematic review was conducted by Vittorini Orgeas et al. which evaluated alveolar socket preservation. They used a metaanalysis on 6 studies and concluded that the use of barrier membranes alone might improve normal wound healing in extraction sites. The authors also confirmed that ridge preservation procedures seem to be effective in limiting horizontal and vertical ridge alterations; however, a cost/benefit evaluation should be taken into account since untreated extraction sites usually show normal healing and the various biomaterials have a wide range of costs [73].

Table 1 shows average results found for the different treatment modalities using the systematic reviews as refer- ences. The numbers are taken from all studies and are not statistically comparable for a meta-analysis.

\section{CONCLUSION}

The literature is substantial in support of site preparation for implant therapy, not just in the esthetic zone but throughout the mouth. Clinicians have long known the benefit of preserving the ridge at the time of extraction to reduce the resorptive process and in many cases to avoid an additional surgical procedure to augment a deficient ridge. This review has given the evidence behind these statements and shown techniques commonly used today. It is apparent that the specific materials are not the key element to successful ridge preservation. Many choices are available to the clinician and success is based on the care at the time of extraction to preserve the remaining walls of the alveolus (extraction socket) through minimal trauma. Ridge preservation is merely one aspect of successful implant therapy, but one that needs to be considered early in the treatment plan by the restorative doctor. It is a cost-effective measure when compared to the need for guided bone regeneration as an additional surgical procedure to treat the resulting ridge defect through augmentation.

\section{CONFLICT OF INTEREST}

The authors report no conflict of interest in preparation of this manuscript.

\section{ACKNOWLEDGEMENTS}

Declared none.

\section{REFERENCES}

[1] Rose LF, Mealey BL, Genco R, Cohen W. Periodontics: medicine, surgery, and implants; Mosby 2004.

[2] Schropp L, Wenzel A, Kostopoulos L, Karring T. Bone healing and soft tissue contour changes following single-tooth extraction: a clinical and radiographic 12-month prospective study. Int J Periodont Restorat Dent 2003; 23(4): 313-24

[3] Ohta Y. Comparative changes in microvasculature and bone during healing of implant and extraction sites. J Oral Implantol 1993; 19(3): 184-98.

[4] Jahangiri L, Devlin H, Ting K, Nishimura I. Current perspectives in residual ridge remodeling and its clinical implications: a review. J Prosthet Dent 1998; 80(2): 224-37. 
[5] Amler MH. The time sequence of tissue regeneration in human extraction wounds. Oral Surg Oral Med Oral Pathol 1969; 27(3): 309-18.

[6] Lin WL, McCulloch CA, Cho MI. Differentiation of periodontal ligament fibroblasts into osteoblasts during socket healing after tooth extraction in the rat. Anat Rec 1994; 240(4): 492-506.

[7] Amler MH, Johnson PL, Salman I. Histological and histochemical investigation of human alveolar socket healing in undisturbed extraction wounds. J Am Dent Assoc 1960; 61: 32-44.

[8] Pietrokovski J. The bony residual ridge in man. J Prosthet Dent 1975; 34(4): 456-62.

[9] Misch CE, Dietsh-Misch F, Misch CM. A modified socket seal surgery with composite graft approach. J Oral Implantol 1999; 25(4): 244-50.

[10] Ashman A. Ridge preservation: important buzzwords in dentistry. Gen Dent 2000; 48(3): 304-12.

[11] Atwood DA. Some clinical factors related to rate of resorption of residual ridges. J Prosthet Dent 1962; 12(3): 441-50.

[12] Yilmaz S, Efeoğlu E, Kiliç AR. Alveolar ridge reconstruction and/or preservation using root form bioglass cones. J Clin Periodontol 1998; 25(10): 832-9.

[13] Younis L, Taher A, Abu-Hassan MI, Tin O. Evaluation of bone healing following immediate and delayed dental implant placement. J Contemp Dent Pract 2009; 10(4): 35-42.

[14] Atwood DA, Coy WA. Clinical, cephalometric, and densitometric study of reduction of residual ridges. J Prosthet Dent 1971; 26(3): 280-95.

[15] Carlsson GE, Bergman B, Hedegard B. Changes in contour of the maxillary alveolar process under immediate dentures: a longitudinal clinical and x-ray cephalometric study covering 5 years. Acta Odontol Scand 1967; 25(1): 45-75.

[16] Soehren SE, Van Swol RL. The healing extraction site: a donor area for periodontal grafting material. J Periodontol 1979; 50(3): 128-33.

[17] Allegrini S, Koening B, Allegrini MRF, et al. Alveolar ridge sockets preservation with bone grafting--review. Ann Acad Med Stetin 2008; 54(1): 70-81.

[18] Schallhorn RG. Postoperative problems associated with iliac transplants. J Periodontol 1972; 43(1): 3-9.

[19] Robinson RE. The osseous coagulum for bone induction technique: a review. J Calif Dent Assoc 1970; 46(1): 18-27.

[20] Diem CR, Bowers GM, Moffitt WC. Bone blending: a technique for osseous implants. J Periodontol 1972; 43(5): 295-7.

[21] Iasella JM, Greenwell H, Miller RL, et al. Ridge preservation with freeze-dried bone allograft and a collagen membrane compared to extraction alone for implant site development: a clinical and histologic study in humans. J Periodontol 2003; 74(7): 990-9.

[22] Goldring SR, Roelke M, Glowacki J. Multinucleated cells elicited in response to implants of devitalized bone particles possess receptors for calcitonin. J Bone Miner Res 1988; 3(1): 117-20.

[23] Committee on Research, Science and Therapy of the American Academy of Periodontology. Tissue banking of bone allografts used in periodontal regeneration. J Periodontol 2001; 72(6): 834-8.

[24] Schwartz Z, Mellonig JT, Carnes DL, et al. Ability of commercial demineralized freeze-dried bone allograft to induce new bone formation. J Periodontol 1996; 67(9): 918-26.

[25] Shapoff CA, Bowers GM, Levy B, Mellonig JT, Yukna RA. The effect of particle size on the osteogenic activity of composite grafts of allogeneic freeze-dried bone and autogenous marrow. J Periodontol 1980; 51(11): 625-30.

[26] Zaner DJ, Yukna RA. Particle size of periodontal bone grafting materials. J Periodontol 1984; 55(7): 406-9.

[27] Mellonig JT, Prewett AB, Moyer MP. HIV inactivation in a bone allograft. J Periodontol 1992; 63(12): 979-83.

[28] Buck B, Malinin TI, Brown MD. Bone transplantation and human immunodeficiency virus: an estimate of risk of acquired immunodeficiency syndrome (AIDS). Clin Orthop Relat Res 1989; 240: 129-36.

[29] Buck B, Resnick L, Shah S, Malinin T. Human immunodeficiency virus cultured from bone: implications for transplantation. Clin Orthop Relat Res 1990; 251: 249-53.

[30] Wood RA, Mealey BL. Histologic comparison of healing after tooth extraction with ridge preservation using mineralized versus demineralized freeze-dried bone allograft. J Periodontol 2012; 83(3): 329-36.
[31] Hoang TN, Mealey BL. Histologic comparison of healing after ridge preservation using human demineralized bone matrix putty with one versus two different-sized bone particles. J Periodontol 2012; 83(2): 174-81.

[32] Eskow AJ, Mealey BL. Evaluation of healing following tooth extraction with ridge preservation using cortical versus cancellous freeze-dried bone allograft. J Periodontol [Epub] 2013; 1-10.

[33] Ten Heggeler JM, Slot DE, Van der Weijden GA. Effect of socket preservation therapies following tooth extraction in non-molar regions in humans: a systematic review. Clin Oral Implants Res 2011; 22(8): 779-88.

[34] Rummelhart J, Mellonig J, Gray J, Towle H. A comparison of freeze-dried bone allograft and demineralized freeze-dried bone allograft in human periodontal osseous defects. J Periodontol 1989; 60(12): 655-63.

[35] Sanders JJ, Sepe WW, Bowers GM, et al. Clinical evaluation of freeze-dried bone allografts in periodontal osseous defects. Part III. Composite freeze-dried bone allografts with and without autogenous bone grafts. J Periodontol 1983; 54(1): 1-8.

[36] Araujo MG, Lindhe J. Ridge preservation with the use of Bio-Oss collagen: a 6-month study in the dog. Clin Oral Implants Res 2009; 20(5): 433-40.

[37] Artzi Z, Tal H, Dayan D. Porous bovine bone mineral in healing of human extraction sockets. Part 1: histomorphometric evaluations at 9 months. J Periodontol 2000; 71(6): 1015-23.

[38] Artzi Z, Tal H, Dayan D. Porous bovine bone mineral in healing of human extraction sockets: 2. Histochemical observations at 9 months. J Periodontol 2001; 72(2): 152-9.

[39] Lee DW, Pi SH, Lee SK, Kim EC. Comparative histomorphometric analysis of extraction sockets healing implanted with bovine xenografts, irradiated cancellous allografts, and solvent-dehydrated allografts in humans. Int J Oral Maxillofac Implants 2009; 24(4): 609-15.

[40] Froum S, Orlowski W. Ridge preservation utilizing an alloplast prior to implant placement--clinical and histological case reports. Pract Periodontics Aesthet Dent 2000; 12(4): 393-402.

[41] Camargo PM, Lekovic V, Weinlaender M, et al. Influence of bioactive glass on changes in alveolar process dimensions after exodontia. Oral Surg Oral Med Oral Pathol Oral Radiol Endod 2000; 90(5): 581-6.

[42] Norton MR, Wilson J. Dental implants placed in extraction sites implanted with bioactive glass: human histology and clinical outcome. Int J Oral \& Maxillofacial implants 2002; 17(2): 249-57.

[43] Froum S, Cho SC, Elian N, Rosenberg E, Rohrer M, Tarnow D. Extraction sockets and implantation of hydroxyapatites with membrane barriers: a histologic study. Implant Dent 2004; 13(2): 15364.

[44] Froum S, Cho SC, Rosenberg E, Rohrer M, Tarnow D. Histological comparison of healing extraction sockets implanted with bioactive glass or demineralized freeze-dried bone allograft: a pilot study. J Periodontol 2002; 73(1): 94-102.

[45] Serino G, Biancu S, Iezzi G, Piattelli A. Ridge preservation following tooth extraction using a polylactide and polyglycolide sponge as space filler: a clinical and histological study in humans. Clin Oral Implants Res 2003; 14(5): 651-8.

[46] Serino G, Rao W, Iezzi G, Piattelli A. Polylactide and polyglycolide sponge used in human extraction sockets: bone formation following 3 months after its application. Clin Oral Implants Res 2008; 19(1): 26-31.

[47] Sclar A. Preserving alveolar ridge anatomy following tooth removal in conjunction with immediate implant placement: the BioCol technique. Atlas Oral Maxillofac Surg Clin North Am 1999; 7(2): 39-59.

[48] Neiva RF, Tsao YP, Eber R, Shotwell J, Billy E, Wang HL. Effects of a putty-form hydroxyapatite matrix combined with the synthetic cell-binding peptide P-15 on alveolar ridge preservation. J Periodontol 2008; 79(2): 291-9.

[49] Fiorellini JP, Howell TH, Cochran D, et al. Randomized study evaluating recombinant human bone morphogenetic protein-2 for extraction socket augmentation. J Periodontol 2005; 76(4): 605-13.

[50] Wang HL, Carroll MJ. Guided bone regeneration using bone grafts and collagen membranes. Quintessence Int 2001; 32(7): 504-15.

[51] Salama H, Salama M. The role of orthodontic extrusive remodeling in the enhancement of soft and hard tissue profiles prior to implant placement: a systematic approach to the management of extraction site defects. Int J Periodontics Restorat Dent 1993; 13(4): 312-33. 
[52] Spray JR, Black CG, Morris HF, Ochi S. The influence of bone thickness on facial marginal bone response: stage 1 placement through stage 2 uncovering. Ann Periodontol 2000; 5(1): 119-28.

[53] Braut V, Bornstein MM, Belser U, Buser D. Thickness of the anterior maxillary facial bone wall-a retrospective radiographic study using cone beam computed tomography. Int J Periodontics Restorat Dent 2011; 31(2): 125-31.

[54] Scantlebury TV. 1982-1992: a decade of technology development for guided tissue regeneration. J Periodontol 1993; 64(Suppl 11): 1129-37.

[55] Hardwick R, Hayes BK, Flynn C. Devices for dentoalveolar regeneration: an up-to-date literature review. J Periodontol 1995; 66(6): 495-505.

[56] Buser D, Bragger U, Lang NP, Nyman S. Regeneration and enlargement of jaw bone using guided tissue regeneration. Clin Oral Implants Res 1990; 1(1): 22-32.

[57] Murphy KG. Postoperative healing complications associated with Gore-Tex periodontal material. Part II. Effect of complications on regeneration. Int J Periodont Restorat Dent 1995; 15(6): 548-61.

[58] Lang NP, Hammerle CH, Bragger U, Lehmann B, Nyman SR. Guided tissue regeneration in jawbone defects prior to implant placement. Clin Oral Implants Res 1994; 5(2): 92-7.

[59] Machtei EE. The effect of membrane exposure on the outcome of regenerative procedures in humans: a meta-analysis. J Periodontol 2001; 72(4): 512-6.

[60] Hoffmann O, Bartee BK, Beaumont C, Kasaj A, Deli G, Zafiropoulos GG. Alveolar bone preservation in extraction sockets using non-resorbable dPTFE membranes: a retrospective non-randomized study. J Periodontol 2008; 79(8): 1355-69.

[61] Walters SP, Greenwell H, Hill M, Drisko C, Pickman K, Scheetz JP. Comparison of porous and non-porous teflon membranes plus a xenograft in the treatment of vertical osseous defects: a clinical reentry study. J Periodontol 2003; 74(8): 1161-8.

[62] Ronda M, Rebaudi A, Torelli L, Stacchi C. Expanded vs. dense polytetrafluoroethylene membranes in vertical ridge augmentation around dental implants: a prospective randomized controlled clinical trial. Clin Oral Implants Res [Epub] 2013.
[63] Bunyaratavej P, Wang HL. Collagen membranes: a review. J Periodontol 2001; 72(2): 215-29.

[64] Marinucci L, Lilli C, Baroni T, et al. In vitro comparison of bioabsorbable and non-resorbable membranes in bone regeneration. $\mathrm{J} \mathrm{Pe}$ riodontol 2001; 72(6): 753-9.

[65] Pitaru S, Tal H, Soldinger M, Noff M. Collagen membranes prevent apical migration of epithelium and support new connective tissue attachment during periodontal wound healing in dogs. J Periodontal Res 1989; 24(4): 247-53.

[66] Blumenthal NM. The use of collagen membranes to guide regeneration of new connective tissue attachment in dogs. J Periodontol 1988; 59(12): 830-6.

[67] Alpar B, Leyhausen G, Gunay H, Geurtsen W. Compatibility of resorbable and non-resorbable guided tissue regeneration membranes in cultures of primary human periodontal ligament fibroblasts and human osteoblast-like cells. Clin Oral Investig 2000; 4(4): 219-25.

[68] Luczyszyn SM, Papalexiou V, Novaes AB, Grisi MFM, Souza SLS, Taba M. Acellular dermal matrix and hydroxyapatite in prevention of ridge deformities after tooth extraction. Implant Dent 2005; 14(2): 176-84.

[69] Darby I, Chen ST, Buser D. Ridge preservation techniques for implant therapy. Int J Oral Maxillofac Implants 2009; 24 Suppl: 260-71.

[70] Horvath A, Mardas N, Mezzomo LA, Needleman IG, Donos N. Alveolar ridge preservation: a systematic review. Clin Oral Investig 2013; 17(2): 341-63.

[71] Morjaria KR, Wilson R, Palmer RM. Bone healing after tooth extraction with or without an intervention: a systematic review of randomized controlled trials. Clin Implant Dent Relat Res [Epub] 2012; 1-20.

[72] Vignoletti F, Matesanz P, Rodrigo D, Figuero E, Martin C, Sanz M. Surgical protocols for ridge preservation after tooth extraction: a systematic review. Clin Oral Implants Res 2012; 23(Suppl 5): 2238.

[73] Vittorini Orgeas G, Clementini M, De Risi V, de Sanctis M. Surgical techniques for alveolar socket preservation: a systematic review. Int J Oral Maxillofac Implants 2013; 28(4): 1049-61.

Received: January 10, 2014

Revised: January 30, 2014

Accepted: February 12, 2014

(C) Tomlin et al.; Licensee Bentham Open.

This is an open access article licensed under the terms of the Creative Commons Attribution Non-Commercial License (http://creativecommons.org/licenses/by-nc/3.0/) which permits unrestricted, non-commercial use, distribution and reproduction in any medium, provided the work is properly cited. 